\title{
COMPARAÇÃO ENTRE TRÊS SISTEMAS DE MANEJO DO SOLO EM CULTURA DE MILHO (1)
}

\author{
CLAUUdo ALVES MOREIRA $\left({ }^{2,7}\right)$, ROMEU BENATTI JUNIOR $\left(^{3,7}\right)$, \\ FERNANDO PICARELLI MARTINS $\left({ }^{4,7}\right)$, GASTĀO MORAES DA \\ SILVEIRA $\left({ }^{5,6,7}\right)$ E JOÃO AURELIANO DE SOUZA COSTA $\left({ }^{5,7}\right)$
}

\begin{abstract}
RESUMO
Três sistemas de manejo do solo em cultura do millho (cultivo convencional, cultivo reduzido e plantio direto) foram comparados do ponto de vista de consumo de combustível e rendimento operacional, mediante a análise de resultados de experimentos realizados em campo de produção da Estação Experimental de Jundiaí, com duração de cinco anos (de 1978/79 a 1982/83). A produtividade, também objeto de análise, foi tomada como fator condicionante. Não foram constatadas diferenças significativas entre os três sistemas quanto à produtividade, tendo, porém, os mesmos diferido entre si quanto ao consumo de combustível e rendimento operacional. O sistema que apresentou menor consumo e exigiu o menor número de horas de trabalho por hectare foi o plantio direto, seguido pelos cultivos reduzido e convencional. O desempenho satisfatório de um cultivador de discos inicialmente desenvolvido para o plantio direto tomou desnecessário o uso de herbicidas na fase de pós-plantio, prótica normalmente empregada no plantio dire to. $O$ fato de os sistemas de manejo terem diferido entre si quanto ao consumo de combustível e rendimento operacional indica que esses fois fatores podem ser considerados numa análise mais ampla para a escolha de um deles.
\end{abstract}

Termos de indexação: sistemas de manejo do solo; cultura do milho.

( $\left.{ }^{1}\right)$ Recebido para publicação em 7 de junho de 1984.

$\left({ }^{2}\right)$ Seção de Máquinas de Colheita e Processamento de Produtos Agrícolas, Instituto Agronômico (IAC), Caixa Postal 28, 13100 Campinas (SP).

$\left({ }^{3}\right)$ Seção de Plantas Fibrosas, IAC.

$\left({ }^{4}\right)$ Estação Experimental de Jundiaí, IAC.

(5) Seção de Máquinas de Movimentação do Solo, IAC.

(6) A tualmente, na Diretoria da Divisão de Engenharia Agrícola, IAC.

( ${ }^{7}$ ) Com bolsa de suplementaçào do CNPq. 


\section{INTRODUÇÃO}

É bastante conhecido o problema mundial da erosão nos solos cultivados, o qual tende a agravar-se na medida do aumento das áreas incorporadas ao processo produtivo e às práticas de mecanização intensiva das culturas. Máquinas cada vez mais potentes permitem ao homem lavrar grandes áreas, aumentando sua capacidade de trabalho; acarretam, porém, uma mobilizaçao excessiva da camada fértil do solo.

Pesquisadores têm questionado a utilização de tais técnicas de produção, de altos custos e causadoras de excessiva erosão e compactação subsuperficial.

FAULKNER (1943) critica a prática corrente, em seu tempo, de realizar a excessiva mobilização do solo, e chega mesmo a afïmar não haver razão científica para a aração. Talvez tenha sido essa a mais polêmica publicação sobre o assunto, despertando outros pesquisadores para o problema.

FREE (1953) aponta três sistemas possíveis de usar na produção: convencional, incluindo aração, gradeação, plantio e cultivos subseqüentes; cultivo minimo ou reduzido, em que o número de operações convencionais de revolvimento do solo é diminuído, e plantio direto (no-till), definido como aquele no qual o solo sofre a menor movimentação que garanta a germinação e crescimento satisfatório das plantas.

BENATTI JR. et alii (1983) comprovaram a superioridade do plantio direto sobre o convencional na redução de perdas por erosão em cultura de milho, em dois solos de São Paulo: Podzolizado de Lins e Marília, variação Marília, e Latossolo Roxo. No primeiro, em terreno com declividade de $10,8 \%$, o plantio direto reduziu de $40 \%$ as perdas de água e de $75 \%$ as de so10 , em relação ao convencional Já no segundo, com declividade de $6,3 \%$, houve $34 \%$ de redução nas perdas de água e $59 \%$ nas de solo.

Estudaram ainda, esses autores, os efeitos dos sistemas convencional, de preparo reduzido e de plantio direto na produtividade de milho em três solos e quatro locais representativos do Estado de São Paulo: Latossolo Roxo (Campinas e Ribeirão Preto); Podzólico Vermelho-Amarelo orto (Mococa); Podzolizado de Lins e Marilia, variação Marília (Pindorama). Não detectaram diferenças significativas entre-as produtividades-dos três sistemas no Latossolo Roxo; no Podzólico Vermelho-Amarelo orto e no Podzolizado de Lins e Marília, variação Marília, os sistemas convencional e cultivo reduzido foram significativamente superiores. Comprovaram também que o plantio direto melhorou a estrutura do Latossolo Roxo (Campinas), aumentando significativamente o tamanho médio de agregados estáveis em água, e que o teor de umidade do solo foi sistematicamente igual ou maior, quando comparado com o do sistema convencional. 
Esses resultados, de maneira geral, dão aos sistemas de cultivo reduzido e plantio direto um caráter de validade do ponto de vista agronômico, quanto à redução das perdas de solo e água e, no caso específico do plantio direto, na melhoria da estrutura do solo, mantendo-se os niveis de produtividade. Com relação a rendimento operacional e consumo de combustível nos três sistemas, os autores apresentam resultados de observações em canteiros experimentais de pequena área. Esses dados, entretanto, năo podem com segurança ser extrapolados porque o rendimento do equipamento motorizado é sensivelmente reduzido devido ao excessivo número de paradas e manobras, além da velocidade de deslocamento mais baixa.

A relativa escassez de dados experimentais obtidos em áreas maiores, com características e problemas mais próximos das condiçðes encontradas nas propriedades rurais, motivou a execução deste experimento. Ele foi orientado no sentido de que dados comparativos de rendimento operacional e consumo de combustível entre os três sistemas, condicionados à não-variação da produtividade, permitam que possíveis diferenças possam ser tomadas como fatores numa análise global para a escolha de um deles.

Uma plantadeira e um cultivador de discos desenvolvidos para o plantio direto foram também utilizados nos outros dois sistemas, tendo seus desempenhos sido avaliados neste trabalho.

\section{MATERIAL E MÉTODOS}

Os experimentos foram realizados na Estação Experimental de Jundiaí, do Instituto Agronômico, em solo Podzolizado Vermelho-Amarelo orto, com cascalho em pequena parte da área (cerca de 5\%), terraceado, com declividade média de $12 \%$.

Os tratamentos correspondentes aos três sistemas avaliados foram: (a) Cultivo convencional: compreendendo aração, gradeação, plantio, cultivo mecânico e adubação em cobertura; (b) Cultivo reduzido: gradeação, plantio, cultivo mecânico e adubação em cobertura; (c) Plantio direto: aplicação de herbicida em pré-plantio, plantio, cultivo mecânico e adubação em cobertura.

Usou-se um delineamento experimental de blocos ao acaso, com quatro repetiçôes. Os tratamentos foram distribuídos aleatoriamente nos blocos, acompanhando curvas de nível e, os blocos, no sentido da declividade do terreno.

Para a avaliação da produtividade, tomaram-se como parcelas linhas de plantas contidas em faixas de terreno entre dois cordões de contorno. 
Em cada parcela, foi determinado o número de balaios de milho em espiga colhidos. A produtividade de milho em grãos foi calculada a partir do peso do material beneficiado correspondente a um balaio de milho em espiga, do número de balaios e da área de cada parcela. Esse procedimento foi seguido em todos os anos agrícolas do experimento.

Os dados do rendimento operacional e consumo de combustível analisados referem-se ao conjunto das operaçōes envolvidas em cada tratamento e em cada ano agrícola.

Para determinação do rendimento operacional, o operador do trator cronometrou cada operação, descontando os tempos de paradas, porém incluindo os de manobras em fins de linha.

O consumo de combustível em cada operação foi determinado através da medição do volume necessário para restabelecer a condição inicial (tanque cheio).

Em razão de os dados referentes a esses dois itens terem sido obtidos para o conjunto de cada tratamento, na análise de variância os anos foram tomados como repetições.

\section{RESULTADOS E DISCUSSĀO}

No caso da produtividade, a análise de variância (split-plot) indicou significância apenas para o fator anos. Como não houve interesse em conhecer o comportamento dos sistemas nos diferentes anos, o restante da análise foi feito objetivando comparar apenas os sistemas. Os resultados, juntamente com os das análises feitas para consumo de combustível e rendimento operacional, são apresentados no quadro 1 .

Como se pode observar, não foram constatadas diferenças significativas em relação a produtividade, entre os três sistemas. Esse resultado diverge parcialmente do obtido por BENATTI et alii (1983), que encontraram diferenças significativas entre o sistema convencional e o plantio direto, em trabalho realizado no mesmo tipo de solo, embora fosse concordante no experimento em solo da região de Campinas (Latossolo Roxo). Essas diferenças viriam reforçar a hipótese levantada pelos autores de que o efeito de local, possivelmente ligado a condições específicas de solo, tenha sido predominante, naquele trabalho, em razão do pequeno tamanho das parcelas.

O conjunto desses resultados indica, de maneira geral, que os três sistemas de manejo não afetam a produ tividade na cultura do milho.

Com relação ao consumo de combustível, houve diferença significativa entre os três sistemas. Como era esperado, em números absolutos o 
QUADRO 1 - Médias de produtividade, consumo de combustível e rendimento operacional, referentes a três sistemas de manejo de solo em cultivo de milho. Estação Experimental de Jundiai, 1978/79 a 1982/83

\begin{tabular}{lccc}
\hline $\begin{array}{l}\text { Sistemas de } \\
\text { manejo }\end{array}$ & Produtividade & $\begin{array}{c}\text { Rendimento } \\
\text { operacional }\end{array}$ & $\begin{array}{c}\text { Consumo de } \\
\text { combustivel }\end{array}$ \\
\hline Convencional & $\mathrm{kg} / \mathrm{ha}$ & $\mathrm{h} / \mathrm{ha}$ & l/ha \\
Cultivo reduzido & 5456 & 10,3 & 45,10 \\
Plantio direto & 5336 & 8,7 & 37,38 \\
$\nu$ & 5448 & 5,2 & 27,50 \\
d.m.s. (Tukey 5\%) & $0,34 \mathrm{n.s}$ & $7,58^{* *}$ & $3,72^{* *}$ \\
d.m.s. (Tukey 1\%) & 861 & - & 9,35 \\
C.V.(\%) & - & 1,46 & - \\
\hline
\end{tabular}

plantio direto apresentou o menor consumo, seguido pelo cultivo reduzido e pelo convencional.

Quanto ao rendimento operacional, constatou-se igualmente diferença significativa entre os três tratamentos: o plantio direto também apresentou o melhor resultado, seguido do cultivo reduzido e, por último, do convencional.

Uma análise baseada unicamente nesses fatores levaria, logicamente, à conclusão de que o plantio direto seria o sistema mais eficiente. No entanto, a sua adoção implica na utilização de herbicidas de pré-plantio, caros e críticos quanto à aplicação, e na necessidade de equipamento especial de plantio, de custo inicial elevado, o que possivelmente diminuiria a vantagem advinda do menor consumo de combustível e do menor número de horas de trabalho exigidas. O sistema de cultivo reduzido, por não estar sujeito às duas restrições citadas, é o que em princípio reúne maiores condições para se revelar mais econômico, considerando não ter havido diferença de produtividade.

Numa análise mais ampla, envolvendo os principais aspectos ligados a custos de produção, esses fatores poderiam servir como elementos diferenciadores na escolha de um dos sistemas, caso os demais custos fossem semelhantes.

A plantadeira desenvolvida para o plantio direto apresentou um desempenho satisfatório em termos de capacidade de penetração e abertura 
de sulco, mesmo em terreno endurecido, devido à forma das ferramentas e à açăo de dois discos lisos cortantes colocados à sua frente, que promovem o corte da resteva e iniciam o cisalhamento do solo. A ferramenta abridora de sulco, pela sua forma, realiza ainda um pré-cultivo bastante eficaz no auxilio de controle do mato nas linhas.

O cultivador de discos apresentou bom desempenho, mesmo em terreno com cerca de $12 \%$ de declividade. Os discos conseguem cortar os restos de cultura e mato, mesmo em condições severas de infestação, realizando eficientemente a "amontoa", que, além de controlar a infestação, contribui para melhorar a fixação das plantas de milho.

O desempenho satisfatório, inclusive no plantio direto, no qual o controle do mato é normalmente feito com aplicação de herbicicas, abre uma nova opção para essa operação.

\section{CONCLUSÕES}

Os três sistemas de manejo, envolvendo diferentes níveis de mobilização do solo, podem ser indiferentemente empregados do ponto de vista da produtividade, na cultura do milho.

Os três sistemas apresentaram diferentes niveis de consumo de combustível e rendimento operacional, tendo o plantio direto os melhores resultados, seguido do sistema de cultivo reduzido.

Numa análise de custos, esses dois fatores poderiam constituir-se em elementos diferenciadores para a adoção de um dos sistemas.

O desempenho satisfatório do cultivador de discos no controle do mato nas entrelinhas, inclusive no sistema de plantio direto, abre nova opção para aquela operação, normalmente realizada com o emprego de herbicidas.

\section{SUMMARY}

THREE SOIL MANAGEMENT SYSTEMS IN CORN CROP: A COMPARATIVE STUDY IN STATE OF SÃO PAULO, BRAZIL

Three crop production systems (namely conventional, reduced tillage and no-till) were compared as to yields, fuel consumption, and number of machine hours per hectare in a five-year experiment (1979/80 to 1982/83) carried out at the Experiment Station in Jundiaí, State of São Paulo, Brazil. No significant differences among treatments were detected in the yields, althought they came up in fuel consumption and number of machine hours. The performance of a disc cultivator was also evaluated. 
The no-till system showed the least values for fuel consumption and number of machine hours, while the reduced tillage showed intermediate results and the conventional system the highest values. The disc cultivator in the no-till system demonstrated the possibility of eliminating the use of herbicides in the inter-row cultivation. Once the three systems showed significant differences in fuel consumption and number of machine hours per hectare but not in the yields, both factors could be taken in consideration in the adoption of one of the systems evaluated.

Index terms: soil management systems; corn crop.

\section{REFERENCIAS BIBLIOGRAFICAS}

BENATTI JR., R. FRANÇA, G.V. \& MOREIRA, C.A. Manejo convencional e reduzido em quatro tipos de solos na cultura do milho em São Paulo. Fundação Cargill, 1983. 68 p.

FAULKNER, E.H. Plowan's folly. New York, Grosset \& Dunlap, 1943. $155 \mathrm{p}$.

FREE, G.R. Mulch tillage in New York. Soil Science Society of America Proceedings, 1.7:165-170, 1953. 